\title{
Construction of Evaluation Index System of supply logistics collaboration based on Supply-Hub Zou Jun ${ }^{1,2}$
}

\author{
${ }^{1}$ Huazhong University of Science and Technology, Wuhan, Hubei, 430074, CHINA \\ ${ }^{2}$ Hubei Communications Technical College, Wuhan, Hubei, 430079, CHINA \\ feifeir_june@163.com
}

Key words- Supply-Hub; supply logistics collaboration; index system

\begin{abstract}
At present, theoretical studies on collaboration evaluation of supply logistics based on Supply-Chain were very few, while almost no researches were on its index system. The paper took supply logistics system based on Supply-Hub as research object, built up a framework of performance evaluation system, analyzed connotation of supply logistics collaboration based on Supply-Hub, adopted literature research as reference for indicators selection and Q-Sort method to test indicators to improve reliability and validity of this evaluation index system, and to provide support for subsequent research on supply logistics collaboration based on Supply-Hub.
\end{abstract}

\section{INTRODUCTION}

Nowadays, life cycle of product is becoming shorter and shorter, while people's personalized demand is more and more diverse, especially for the assembly type supply chain. In this kind of supply chain, parts processing and product assembly are separated into different regions, even different countries. Moreover, suppliers are numerous, kinds of parts are huge, and processing technologies are diverse, which result in very complex relationship in production process and heavy tasks in planning, organization and coordination. Parts suppliers are independent interest subjects, so it is difficult to achieve collaboration with traditional management methods. If one certain part of one supplier delays in delivery, the entire production line will be seriously affected, even shutdown, which greatly weakens the competitiveness of supply chain. Therefore, improving coordination of supply logistics, and making huge parts of different suppliers synchronize, will enhance response ability of supply chain, and improve enterprise performance significantly.

As an important management tool and technology to solve supply logistics collaboration, Supply-Hub has been applied to supply chain system, and plays an important role in supply logistics collaboration. Then, how to effectively measure the important role of Supply-Hub in Supply logistics collaboration needs to establish effective performance evaluation indicators of supply logistics collaboration based on Supply-Hub, and establish an effective improvement channel, so as to promote the development of supply logistics collaboration, and to improve the performance of supply chain operation in a long period.

In recent years, researches on supply chain collaboration performance have been gradually taken seriously by experts and scholars. There are very few studies involve supply logistics collaboration performance, and even less about researches of collaboration performance based on this new organizational management mode of Supply-Hub. Therefore, this paper will focus on establishing index system of supply logistics collaboration based on Supply-Hub, lay the foundation for subsequent research, and provide basis to measure supply logistics collaborative performance of supply chain enterprises.

\section{FRAMEWORK OF PERFORMANCE EVALUATION SYSTEM}

To construct performance evaluation system, basic elements must be clear first. That is, performance evaluation system should solve what to evaluate, how to evaluate, and what is the evaluation results, etc[1].. Combined with performance evaluation goal of supply logistics collaboration based on Supply-Hub, the paper built up this performance appraising system with 
seven aspects including performance evaluation object, performance evaluation basic model, performance evaluation index system, performance evaluation standard, evaluation methods, performance evaluation organization and conclusions (as shown in figure 1).

\section{A. Performance evaluation object}

In this system, the object of performance evaluation is supply logistics collaboration system based on Supply-Hub, mainly measured by implementation of goals of all stakeholders in this supply logistics system, including suppliers, third-party logistics enterprise operating Supply-Hub, and manufacturers. Since members of this supply logistics system are numerous, measurement is of great difficulty, whole performance of supply logistics collaboration system should be combined with system goals, each member's goals, as well as the key business processes together.

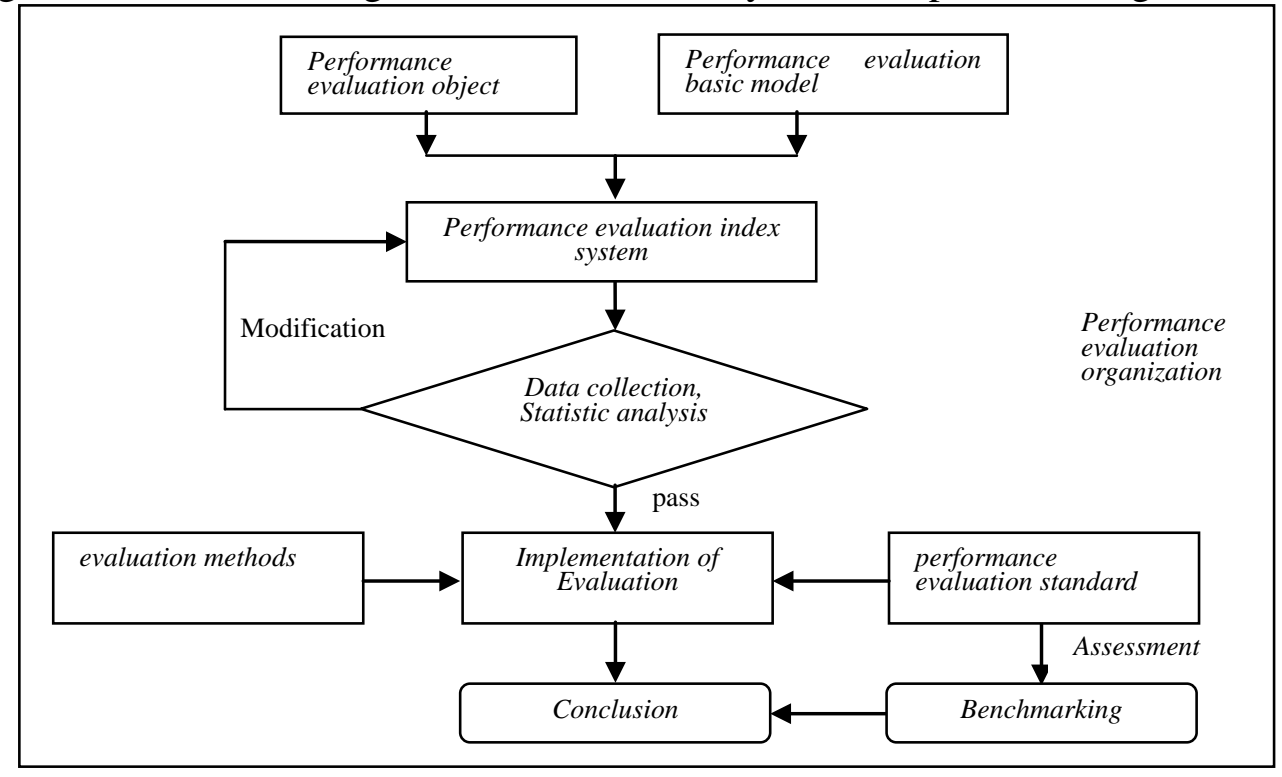

Figure 1 Basic Framework of Performance Evaluation System

\section{B. Performance evaluation basic model}

Performance evaluation basic model is the reference model in constructing performance evaluation index system. In supply chain Performance evaluation, the most frequently used and representative evaluation methods are finance-oriented Return on Investment (ROI) evaluation system, responsibility-oriented Key Performance Indicators (KPI) evaluation system, process-oriented Supply Chain Operations Reference Model (SCOR) evaluation system, and strategy-oriented Balanced Scorecard (BSC) evaluation system. By now, a typical model of Collaborative Performance System was put forward by Simatupang \& Sridharan in 2004[2](as shown in Figure 2). As literatures about performance evaluation of Supply logistics synergy are very few, this article will refer to SCOR model, as well as model put forward by Simatupang \& Sridharan, combining with the connotation of supply logistics collaboration, build up performance evaluation index system of supply logistics based on Supply-Hub. 


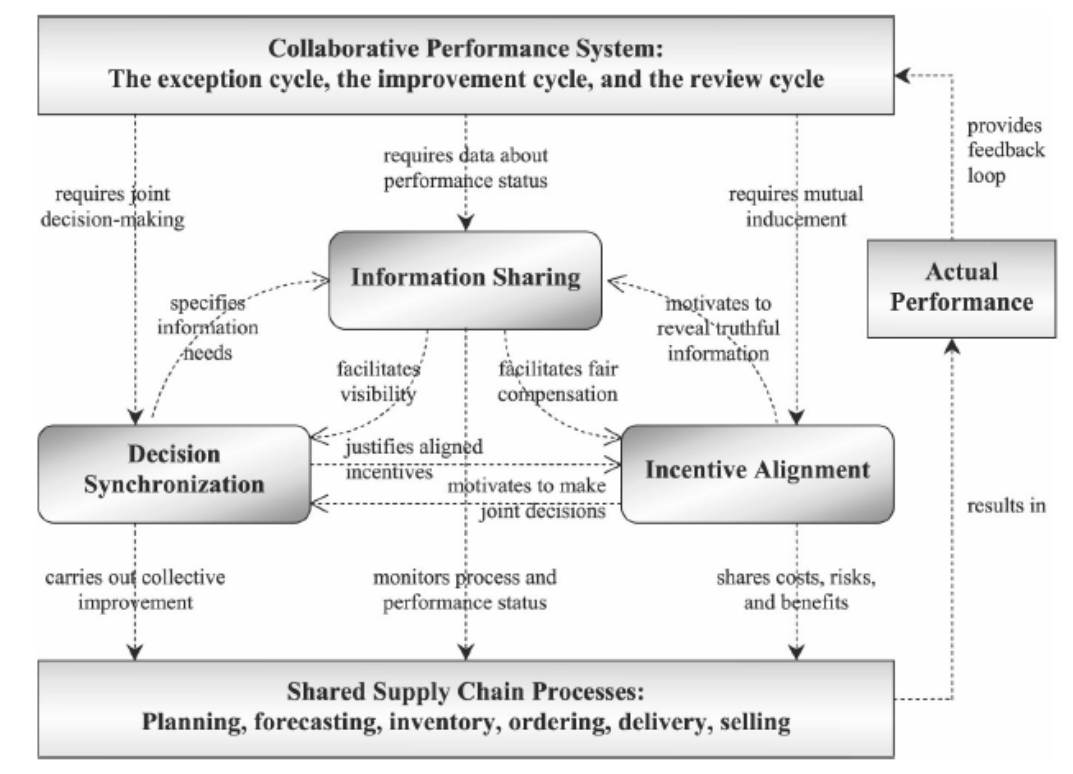

Figure 2 Collaborative Performance System of Supply Chain (Simatupang \& Sridharan, 2004)

\section{Performance evaluation index system}

Performance evaluation index system refers to key indicators by which measure the performance. The index system is the basis of implementing performance evaluation, which contains qualitative indexes and quantitative indexes, and will be described in detail in the following content.

\section{D. performance evaluation standard}

Performance evaluation standard is criterion to determine evaluation results, also known as "benchmark". Selection of evaluation standard is mainly based on evaluation targets and expectations. Evaluation indexes must have metrics, which make the evaluation results comparable, so as to ensure the realization against goals. In practice, quantitative indicators can be determined by consulting past performance data of system and subsystem, future expectations of targets, as well as performance data from competitors, then can be judged from completion, improvement and development. As to qualitative indexes, evaluation standards level can be determined through discussion, Delphi method and questionnaire.

\section{E. Performance evaluation method}

Performance evaluation method is a specific tool to get ultimate evaluation results through calculation of specific parameter values which are compared with evaluation criteria. it is concluded that no right conclusions can be drew without scientific evaluation method. Since so many stakeholders are in supply logistic collaboration system based on Supply-Hub, and every enterprise is independent interest individual, this collaboration system, which is a multi-objective complicated system, has numerous indexes, and can be evaluated by multi-objective synergy degree evaluation model.

\section{F. Performance evaluation organization}

Performance evaluation organization means who is responsible for constructing performance evaluation system, and organizing the evaluation. Supply logistics coordination system based on Supply-Hub involving numerous enterprises, most of whom are cooperative relationship, it is difficult for an organization to build up performance evaluation system, and put it into practice. Also, it is very difficult to establish effective rewards and punishments measures, so performance evaluation of supply logistics system is totally different from that within the enterprise. As a result, well-organized supply chain system may take core enterprise, which in most cases is core manufacturer for processing and assembly type supply chain, as initiator, and invite key business partners in supply chain to participate in to build up evaluation system together. This system is established in consultation according to general goals, reflecting common interests of all members, 
making member enterprises reach a consensus on system performance evaluation indicators, standards, methods, etc., so as to effectively promote and implement systematic performance evaluation, and to achieve the realization of overall goals.

\section{G. Performance evaluation conclusion}

Performance evaluation conclusion is the output of performance evaluation system, and the final evaluation of the whole system after indexes building, data collection, statistical analysis, and evaluation, which provides a reference frame for decision-makers.

The above seven parts contact each other, work together, constitute a complete performance evaluation system.

\section{DESIGN THE EVALUATION SYSTEM}

\section{A. Connotation of Supply logistics collaboration Based on Supply - Hub}

The paper defines supply logistics collaboration as: Based on resource integration of supply chain, through management modes and technical means such as information sharing and centralized pickup, the supply of parts and semi-finished products suppliers in supply chain can achieve vertical synchronization with manufacturer's production plan and MRP; while can horizontally match with other related suppliers in supply chain at the same time, and can reduce phenomena such as order delivery delays and inventory costs rise due to lack of supplies, which eventually improves the performance of a supply chain.

Combined with the process of supply chain, connotation of supply logistics collaboration based on Supply - Hub should mainly includes the following contents. Here, third-party logistics enterprise operating Supply-Hub is expressed in 3PL.

(1) Synergy between 3PL and downstream manufacturer. It means that 3PL and downstream manufacturer establish long-term cooperative partnership, carry out demand forecasting and production planning jointly, to improve both quality of products and services, so as to promote overall efficiency and value of supply chain.

(2) Synergy between 3PL and upstream suppliers. It means that 3PL carries out Milk-Run among suppliers according to downstream production plan and demand. Demand of downstream manufacturers is well satisfied through fully information sharing and collaborative development between 3PL and suppliers.

(3) Collaboration among suppliers. Demand for various parts is closely related, therefore, in order to achieve supply logistics collaboration, coordination among various suppliers are needed besides coordination between upstream and downstream enterprises. Interaction among suppliers will be promoted and downstream demand will be better satisfied through improving collaboration among suppliers.

(4) Logistics service capability. It mainly includes order organization and completion capability and logistics service improvement capability, which are mainly reflected in collaboration level, timeliness of distribution, quality and efficiency of logistics service of 3PL. Logistics service capability plays a very important role in supply chain collaboration.

(5) Collaborative support of 3PL. It mainly refers to realization of plan, organize and control activities in logistics and overall improvement of supply logistics process besides storage, transportation, sorting, distribution and other logistics links. Through collaborative support of 3PL, goals of time compression, waste reduction, cost control, flexible response, information sharing, etc. are achieved.

\section{B. Index selection}

Good content validity is a basic requirement of index system, which can be improved by fully literatures study and interviewing with relevant personnel and experts (Hensley, 1999) [3]. In order to guarantee the validity of index system, project team carried out field investigation of assembly type supply chain enterprises for many times, including DONGFENG Automobile, DONGFENG-CITROEN Automobile, BMW, ZTE, etc., and their spare parts manufacturers. 
Combined with a large number of literatures research and connotation of supply logistics synergy based on Supply-Hub, the initial index system was built up, including five first class indicators, 25 second class indicators (as shown in table 1). Among them, third-party logistics enterprise operating Supply-Hub is expressed in 3PL.

Related literatures are introduced briefly in the following content.

(1) Synergy between 3PL and downstream manufacturer. Liao Chenglin \& Liu Xueming (2008) put forward indicators while analyzing effects of supply chain management implementing on organizational performance, including first class indicators of strategic and cooperative partnership with suppliers, customer relationship, and second class indicators of communication with customers often, measuring customer satisfaction often, regular evaluating relationship with customers, customers' feedback for our products or services, sharing knowledge of core business processes, etc.[4]. Braunscheidel \& Suresh (2009) evaluated agile supply chain and designed scale including: customers' feedback for quality and transportation performance, information sharing with customers, sharing production planning with customers, and sharing inventory information with customers[5]. Xie Lei (2012) in the study of two dimension collaboration theory of supply logistics built a scale including downstream manufacturers carrying out joint demand forecasting, joint production plan and other indicators [6].

(2) Synergy between 3PL and upstream suppliers. Sanders (2007) put forward collaboration indicators of an organization including timely sharing information with suppliers and cross-functional business process, encouraging collaborative planning with suppliers, etc [7]. Huang et al. (2008) pointed out that outward learning ability measurements include keeping close communication with key suppliers and customers' feedback for quality and transportation performance, etc [8]. Singh and Power (2009) studied effects and characteristics of coordination among enterprises with their suppliers and customers in supply chain, variables in research include customer relationship, supplier involvement and enterprise performance. "Considering interests of suppliers while setting goals", "Providing information to suppliers to help them improve quality and responsiveness" are served as measurements of supplier involvement [9]. Xie Lei (2012) put forward indicators of sharing information with suppliers in the evaluation of supply logistics coordination[6].

(3) Collaboration among suppliers. Modi and Mabert (2007) stated indicators in study of supplier performance, which include field investigation to enhance mutual understanding and awareness of their products, expected suppliers getting helpful information from other organizations and providing required information to other organizations[10]. Mondragon and Lyons (2008) suggested suppliers collaborating production scheduling plan in supply chain, which could significantly improve efficiency [11]. De Boeck and Vandaelee (2008) stated that measurement indexes of operating synergy includes combined order management, sharing demand and sales information, sharing operational plan, etc. [12]. Long Yue et al. (2010) pointed out that coordination of multiple auto parts suppliers could reduce the overall operating costs [13].

(4) Logistics service capability. Panayides and So $(2005,2007)$ stated that indicators to measure efficiency of logistics service includes on time transport service, timely response to customer demand, saving customer records accurately and precisely acquire and transfer information, etc. [14][15]. Kaynak and Hartley (2006) designed JIT procurement research scale, including transport capacity and delivery batch, etc. [16]. Ma Shihua et al. (2007) studied logistics capability, and found that matching ability had significant positive influence on responsiveness, quality of service and logistics performance [17].

(5) Collaborative support of 3PL. Literatures about this content is very few. Xu Wenxia (2011) evaluated automobile industry supply chain, and put forward indicators including members average participation years, accuracy of information transmission, information extent, etc.[18].

\section{Construction of initial evaluation index system}

Combining with the above literatures research, and connotation of supply logistics collaboration model based on Supply-Hub, the initial evaluation index system is designed, as shown in Figure 3. 


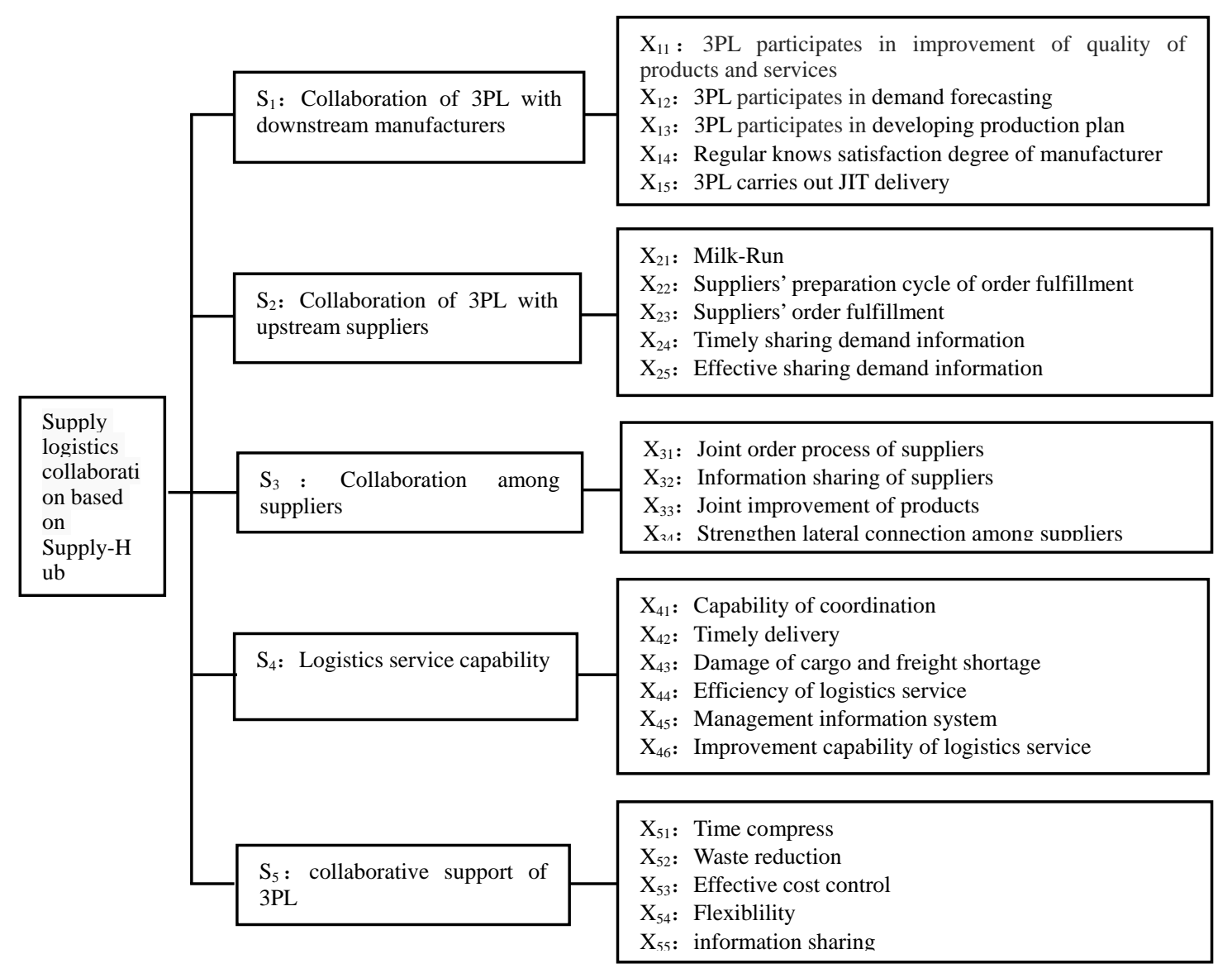

Figure3 Initial evaluation index system

\section{Test}

In order to further improve validity and reliability of indexes, the initial index system should be tested. The index system was screened by application of classification method (Q - sort) put forward by Moore and Benbasat (1991), which excluded indexes considered unreliable by experts, modified fuzzy or ambiguous indicators, and added indicators recognized practicable unanimously by most experts at the same time, to ensure coverage and credibility of index system[19]. Specific process is as follows.

(1) Twelve research experts and scholars engaged in supply chain management, and personnel of enterprises were invited and divided into four groups, each group having three people. Each group participated in one round of testing and was interviewed separately. That is, group 1 for Round 1 test, group 2 for Round 2 test, group 3 for Round 3 test, and group 4 for Round 4 test.

(2) All indicators were disorganized. During Round 1, test subjects divided all indicators into five groups according to their own understanding. During Round 2, test subjects divided all indicators into five groups according to first class indicators in above index system which were named as "synergy between 3PL and downstream manufacturer ", "synergy between 3PL and upstream suppliers", "collaboration among suppliers", "logistics service capability", "collaborative support of 3PL". According to results of Round 1 and Round 2, indicators considered unreasonable by at least 2 experts were deleted, and expression of indicators was corrected to prevent incomprehension and ambiguity. Meanwhile, indicators considered reasonable by at least 2 experts were added into index system.

(3) The modified index system was tested repeatedly by group 3 and group 4 redoing the prior steps to guarantee the stability and efficiency of test results.

(4) After testing, final evaluation index system was formed, including five first-class indicators and 29 second class indicators, as shown in table 1. 
Table 1 Evaluation index system of supply logistics collaboration based on Supply-Hub

\begin{tabular}{|c|c|c|}
\hline $\begin{array}{l}\text { First class } \\
\text { indicators }\end{array}$ & Second class indicators & Characters \\
\hline \multirow{6}{*}{$\begin{array}{c}\mathrm{S}_{1} \text { : Collaboration } \\
\text { of 3PL with } \\
\text { downstream } \\
\text { manufacturers }\end{array}$} & Satisfaction of Manufacturers & Quantitative \\
\hline & Accuracy of demand forecasting & Quantitative \\
\hline & Timely fulfillment rate of production plan & Quantitative \\
\hline & Delivery accuracy & Quantitative \\
\hline & Approbation degree of partnership & Qualitative \\
\hline & Identification of manufacturer's enterprise value & Qualitative \\
\hline \multirow{5}{*}{$\begin{array}{c}\mathrm{S}_{2}: \text { Collaboration } \\
\text { of 3PL with } \\
\text { upstream } \\
\text { suppliers }\end{array}$} & The average Milk-Run cycle & Quantitative \\
\hline & The average purchasing lead time & Quantitative \\
\hline & Supplier order completion rate & Quantitative \\
\hline & Requirement production rate (RPO) of suppliers & Quantitative \\
\hline & Information agility & Qualitative \\
\hline \multirow{5}{*}{$\begin{array}{l}\mathrm{S}_{3}: \text { Collaboration } \\
\text { among suppliers }\end{array}$} & Parts matching rate & Quantitative \\
\hline & Suppliers' exploitation degree of information & Qualitative \\
\hline & Suppliers average response time & Quantitative \\
\hline & Parts receiving rate & Quantitative \\
\hline & Recognition among suppliers & Qualitative \\
\hline \multirow{5}{*}{$\begin{array}{c}\mathrm{S}_{4} \text { : Logistics } \\
\text { service capability }\end{array}$} & Total cycle of order completion & Quantitative \\
\hline & Timely arrival rate & Quantitative \\
\hline & Cargo damage and shortage rate & Quantitative \\
\hline & Timely response rate & Quantitative \\
\hline & Resolution rate of customers problems & Quantitative \\
\hline \multirow{8}{*}{$\begin{array}{l}\mathrm{S}_{5}: \text { Collaborative } \\
\text { support of 3PL }\end{array}$} & Average inventory turnover & Quantitative \\
\hline & Total order fulfillment rate & Quantitative \\
\hline & Logistics cost reduction rate & Quantitative \\
\hline & Average supply time flexibility & Quantitative \\
\hline & Innovation ability of product, service and process & Qualitative \\
\hline & $\begin{array}{l}\text { Convenience and effectiveness of management information } \\
\text { system }\end{array}$ & Qualitative \\
\hline & Width of information & Qualitative \\
\hline & Average participation years of $\quad$ Supply chain members & Quantitative \\
\hline
\end{tabular}

\section{SUMMARY}

At present, very few literatures studied on collaboration degree evaluation of supply logistics, not to mention literatures about collaboration evaluation of supply logistics based on Supply-Hub. In order to better evaluate collaboration degree of supply logistics based on Supply-Hub, establishment of index system is of great importance. A full investigated and studied, wide covered, goal-oriented index system plays a strong guiding and promoting role in realization of general objectives. For the sake of establishing an effective and useful index system, literature research was adopted for indicators selection, and Q-Sort was used for indicators testing, which helped construction of a reliable and valid evaluation index system, and provided support for subsequent synergy degree study.

\section{Acknowledgement}

Paper supported by Project "Collaboration Theory and Method Research of Supply Logistics Based on Supply-Hub ” of Natural Science Foundation of China (Grant No. 71072035). 


\section{REFERENCES}

[1] Qu Shengen. "Study on Performance Evaluation System of Supply Chain”. Doctor Degree thesis. Harbin, Heilongjiang, China: Harbin Engineering University, 2006. (in Chinese)

[2] Simatupang T.M., Sridharan R.. A benchmarking scheme for supply chain collaboration [J]. Benchmarking: An International Journal, 2004, 11(1): 9 30.

[3] Hensley R.L. A review of operations management studies using scale development techniques [J]. Journal of Operations Management, 1999, 17 (3): 343-358.

[4] Liao Chenglin, Liu Xueming. An Analysis on the Impact of Supply Chain Management Practice on Organizational Performance[J]. Chinese Journal of management science, 2008, 16 (3) : 116-124. (in Chinese)

[5] Braunscheidel M.J., Suresh N.C. The organizational antecedents of a firm's supply chain agility for risk mitigation and response [J]. Journal of Operations Management, 2009, 27(2): 119-140.

[6] Xie lei, Ma shihua, Gui huaming, etc.. The Relationship Among Supply Logistics Synchronization, Supply Chain Agility, and Firm Performance[J]. Science Research Management, 2012,(11): 96 104. (in Chinese)

[7] Sanders N. R. An empirical study of the impact of e-business technologies on organizational collaboration and performance [J]. Journal of Operations Management, 2007, 25(6): 1332-1347.

[8] Huang X.W., Kristal M.M., Schroeder R.G. Linking learning and effective process implementation to mass customization capability [J]. Journal of Operations Management, 2008, 26 (6): 714-729.

[9] Singh P. J., Power D. The nature and effectiveness of collaboration between firms, their customers and suppliers: a supply chain perspective [J]. Supply Chain Management: An International Journal, 2009, 14(3): 189-200.

[10] Modi S.B., Mabert V. A. Supplier development: Improving supplier performance through knowledge transfer [J]. Journal of Operations Management, 2007, 25 (1):42-64.

[11] Mondragon A.E.C., Lyons A.C. Investigating the implications of extending synchronized sequencing in automotive supply chains: The case of suppliers in the European automotive sector.[J]. International Journal of Production Research, 2008, 46(11):2867-2888.

[12] De Boeck L., Vandaelee N. Coordination and synchronization of material flows in supply chains: An analytical approach [J]. International Journal of Production Economics, 2008, 116(2): 199-207.

[13] Long Yue, Yi Shuping. Analysis on Cooperation Effect Among Homogeneous Auto Parts Suppliers Embedded by the Manufacturing Service [J]. Science Research Management, 2010, 31 (4) : 102-110. (in Chinese)

[14] Panayides P.M., So M. Logistics service provider-client relationships [J]. Transportation Research Part E, 2005, 41(3): 179-200.

[15] Panayides P.M. The impact of organizational learning on relationship orientation, logistics service effectiveness and performance [J]. Industrial Marketing Management, 2007, 36(1): 68-80.

[16] Kaynak H., Hartley J.L. Using replication research for just-in-time purchasing construct development [J]. Journal of Operations Management, 2006, 24(6): 868-892.

[17] Ma Shihua, Tan Yong, Gong Fengmei. An Empirical Research: Relationship Between Logistics Capabilities and Supply Chain Performance in Industrial Enterprises[J]. Chinese Journal of Management, 2007, 4 (4) : 493-500. (in Chinese)

[18] Xu Wenxia. Performance Evaluation and Application of Automotive Industry Supply Chain Collaboration [J]. Mathematics in Practice and Theory, 2011, (11) : 58-66. (in Chinese)

[19] Moore G.C., Benbasat I.. Development of an instrument to measure the perceptions of adopting an information technology innovation [J]. Information Systems Research, 1991, 2(2): 192-222. 